\title{
Comparison of Urinary PAHs among Firefighters and Asphalt Pavers
}

\author{
Theodore L. Aquino, Giffe T. Johnson, Thomas Truncale, Raymond D. Harbison \\ Environmental and Occupational Health Department, College of Public Health, University of South Florida, Tampa, FL, USA \\ Email: gjohnson@health.usf.edu
}

How to cite this paper: Aquino, T.L., Johnson, G.T., Truncale, T. and Harbison, R.D. (2017) Comparison of Urinary PAHs among Firefighters and Asphalt Pavers. Occupational Diseases and Environmental Medicine, 5, 39-46.

https://doi.org/10.4236/odem.2017.52004

Received: February 4, 2017

Accepted: May 15, 2017

Published: May 19, 2017

Copyright $\odot 2017$ by authors and Scientific Research Publishing Inc. This work is licensed under the Creative Commons Attribution International License (CC BY 4.0).

http://creativecommons.org/licenses/by/4.0/ (c) (i) Open Access

\begin{abstract}
Objective: The purpose of the investigation is to examine urinary biomarkers of polycyclic aromatic hydrocarbon (PAH) exposure among firefighters and asphalt workers. Methods: Average concentrations of urinary PAHs were used for comparative analysis between groups of firefighters and asphalt pavers. Microsoft Excel was used to perform calculations and the t-test was utilized for statistical analysis. Results: When compared to the National Institute of Standards and Technology (NIST) standard for smokers and non-smokers, firefighters demonstrated various statistically significant differences in urinary PAH concentrations. Asphalt workers had statistically significant higher urinary concentrations in three PAHs as compared to the NIST smoker mean. Conclusions: Firefighters did not demonstrate a substantial change in urinary PAH metabolite levels when compared to controls. Asphalt pavers experienced concentrations that were in some cases increased by orders of magnitude compared to controls.
\end{abstract}

\section{Keywords}

PAHs, Firefighters, Asphalt Workers, Urinary Biomarkers

\section{Introduction}

Cancer amongst firefighters is an international topic of interest. Awareness that cancer was a potential occupational hazard amongst firefighters became pervasive during the 1990s. Firefighters are exposed to an array of compounds during their service, including polycyclic aromatic hydrocarbons (PAHs) [1]. Firefighters are not only exposed to PAHs during fire suppression operations, but also when conducting an overhaul of turnout gear and by living in potentially contaminated fire houses if proper decontamination of equipment is not conducted [1].

PAHs are a class of organic compounds produced by incomplete combustion 
or high pressure processes [2]. PAHs often consist of three or more fused benzene rings composed of only carbon and hydrogen. There are 18 PAHs that are commonly produced during fires [3]. Of these, the World Health Organization's International Agency for Research on Cancer (IARC) classifies one as being carcinogenic to humans (benzo [a] pyrene) and eight others as being possibly or probably carcinogenic to humans for lung, skin, and bladder cancers [4]. Smoke contains particulate and gaseous phases, both of which contain PAHs [1].

When actively suppressing fires, firefighters typically wear protective ensembles that are compliant with NFPA standards and a Self-Contained Breathing Apparatus (SCBA). Even when properly utilizing the aforementioned protective equipment, it has been demonstrated that firefighters have the potential to absorb PAHs during fire suppression activities [3]. However, the exposure may be insufficient to contribute to the carcinogenic process. In epidemiological studies, cancer outcomes in firefighters have been inconclusive.

For instance, Hanson 1990 [5] suggested an association between firefighters and lung cancer, but it is a singular finding among 12 other studies that find no increase in risk for lung cancer among firefighters [6]-[17]. While the LeMasters et al. 2006 [15] study detected a weak association between skin cancer and firefighting, 7 other studies refute this finding [6] [8] [9] [12] [14] [16] [17]. As well, for bladder cancer, a few studies detected weak associations with firefighting [9] [14] [16] [17], but these findings are refuted by 7 other studies that determined no association was present [6] [7] [8] [10] [11] [12] [15].

Another occupational group that may have substantive PAH exposure is asphalt laying workers. Asphalt, also known as bitumen, is primarily utilized in the United States for road paving and exposure is known to potentially cause DNA damage [18]. It contains a mixture of polycyclic aromatic compounds which lead asphalt pavers to be exposed to PAHs. PAH metabolites are accepted biomarkers for monitoring exposure to asphalt emissions [19] [20] and urinary 1-OH-Pyrene has proven to be a favorable predictor of oxidative DNA damage, specifically in asphalt exposed workers [21]. Urinary PAHs in asphalt pavers is associated with both inhalation and dermal exposure [22], with dermal exposure being the primary route [23] [24]. Scientific evidence exists to suggest that asphalt pavers have an excess risk of cancer, although it is inconclusive and unclear if the increased cancer risk is secondary to only asphalt exposure or a combination of asphalt, diesel oil, tobacco and tar exposure [23]. In 2015, Rhomberg et al. performed a robust investigation to examine quantitative risks for roofing workers exposed to asphalt. It was reported that epidemiology studies do not consistently report elevated risks, nor do they have sufficient exposure evidence or satisfactory control for confounders. As such, much of the existing data was deemed inadequate for dose-response analysis. When Environmental Protection Agency consistent time-to-tumor model methods were applied to quantify potential cancer risks, roofers (with both dermal and inhalation exposure to asphalt) had cancer risks within a range typically considered acceptable within regulatory frameworks [25]. 
The purpose of the current investigation is to examine urinary biomarkers of $\mathrm{PAH}$ exposure among firefighters and asphalt workers to determine if these occupational groups are appropriate for further investigation regarding cancer risk from $\mathrm{PAH}$ exposure.

\section{Methods}

In 2014, the National Institute of Standards and Technology (NIST) developed two new Standard Reference Materials (SRMs), SRM 3672 Organic Contaminants in Smokers' Urine (frozen) and SRM 3673 Organic Contaminants in NonSmokers' Urine (frozen), which included polycyclic aromatic hydrocarbons (PAHs). This standard was derived by combining data from: NIST, the Centers for Disease Control and Prevention (CDC), and the Institute National de Santé Publique du Québec (INSPQ). This data was used as a comparison group for urinary PAH biomarker data derived from firefighters and asphalt pavers.

In 2003, the CDC published a case control study [26] which compared blood and urine specimens of firefighters who responded to the World Trade Center (WTC) disaster to firefighters who were not present at the WTC. Sampling occurred 3 weeks after September 11, 2001. A total of 110 potentially fire related chemicals were analyzed, including urinary PAH metabolites. The study had 318 WTC disaster exposed firefighters and 47 firefighter controls who were not at the WTC. Urinary PAH data was ultimately collected for four cohorts: control firefighters (unexposed to field activity), firefighters who were present at the WTC collapse, firefighters who were present on WTC post-collapse days 1 and 2 but were not present at collapse, and special operations command firefighters.

In 2012, a study using urinary biomarkers of PAHs to guide exposure-reduction strategies among asphalt pavers was conducted. Urine samples $(n=480)$ were collected from 12 paving workers over 3 workdays during 4 workweeks. Preshift, postshift, and bedtime urine samples were collected and analyzed for 1-OH-pyrene; 1-, 2-, 3-, 4-OH-phenanthrene; 1-, 2-OH-naphthalene; and 2-, 3-, 9-OH-fluorene. Each of the 4 weeks represented a different exposure scenario: a baseline week (normal conditions), a dermal protection week (protective clothing), a powered air-purifying respirator (PAPR) week, and a biodiesel substitution week (100\% biodiesel provided to replace the diesel oil normally used by workers to clean tools and equipment) [23]. The baseline data from nominal work conditions were used in this study to make comparisons to relative PAH biomarker levels in asphalt workers, firefighters, and the general population.

Subjects from all groups were selected based on the presence of a measured urinary sample of the indicated PAHs. As this data had been previously collected and data based by their respective project programs, all data was selected for use. Unfortunately, demographic data was not available for all subjects and was not included in the analysis. Average concentrations of each urinary PAH were calculated and used for comparative analysis between all groups. Microsoft Excel was used to perform calculations and the t-test was utilized for statistical analysis to determine statistically significant differences in biomarker concentrations 
between groups with a p-value of $<0.05$ being considered statistically significant.

\section{Results}

When compared to the NIST standard for smokers and non-smokers, firefighters demonstrated statistically significant differences in urinary concentrations for the following metabolites: 2-OH-fluorene, 3-OH-fluorene and 1-OH-pyrene, which were lower in firefighters than the NIST mean for smokers. 1-OH-phenanthrene, 2-OH-phenanthrene and 3-OH phenanthrene were higher among world trade center exposed firefighters than the NIST mean for smokers. When firefighters were compared to the NIST non-smoker standard, firefighters demonstrated elevated levels in all tested PAH biomarkers due to a mixture of smokers and nonsmokers in the firefighter cohort. Asphalt workers had statistically significant higher urinary concentrations of 2-OH-fluorene, 1-OH-phenanthrene and 3-OH-phenanthrene as compared to the NIST smoker mean. The results of statistical analyses between firefighter and asphalt paver cohorts are summarized in Figure 1.

As 1-OH-Pyrene is the only PAH classified as a known human carcinogen, the results of this biomarker data are of particular importance to potential health outcomes. Firefighter biomarker levels all measured in between the range of smokers and non-smokers, which is expected of the firefighter groups considering they contained a mixture of smokers and non-smokers. However, asphalt paver biomarker concentrations were statistically significantly elevated above those found in smokers and were nearly 3 fold higher on average.

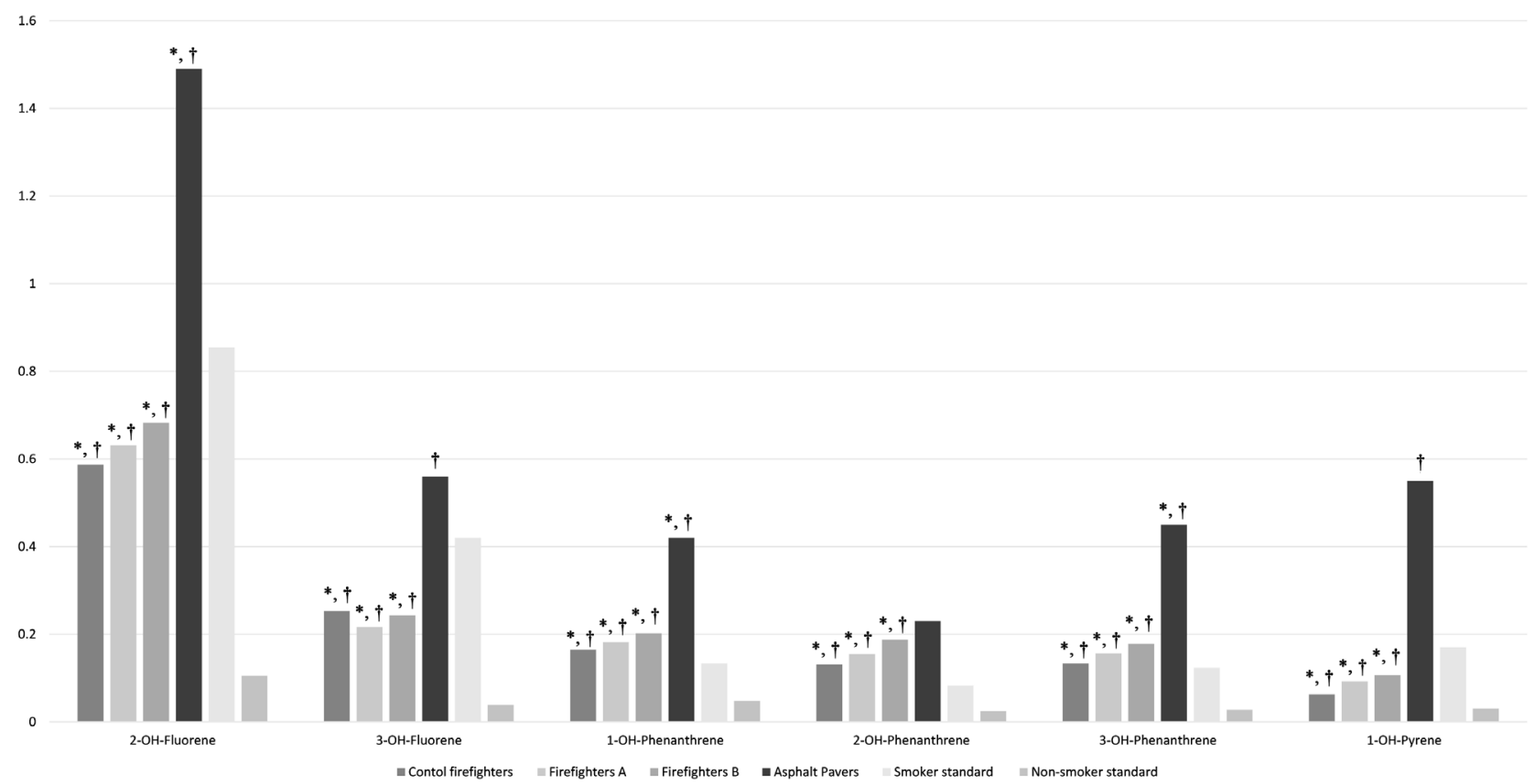

Figure 1. Comparison of mean PAH urinary concentrations (ng/ml). Firefighters A represent those present at the WTC collapse. Firefighters B represent those who were present on WTC post-collapse days 1 and 2 but were not present at collapse. ${ }^{*}$ indicates $p$ $<0.05$ compared to mean urinary concentrations of mean smoker standard population. $\dagger$ indicates $p<0.05$ compared to mean urinary concentrations of mean non-smoker standard population. 


\section{Discussion}

The findings reported here indicate that the sample of firefighters produced expected concentrations of urinary PAHs relative to the general population considering that the sample consisted of smokers and non-smokers, and the average concentrations fell between those of non-smokers and smokers in the general population for several PAHs. Of particular importance is the finding of near background levels of 1-OH-Pyrene found in the Firefighter samples as that is the only PAH conclusively demonstrated to be carcinogenic.

Asphalt pavers, however, produced higher than background PAH concentrations for all types measured. Considering that the data used for comparison in this study was derived from a program designed to reduce exposure to workers, the averages reported here likely represent "best case" concentrations. It is important to note, though, that due to the lack of dose-response data that exists for PAH biomarkers and cancer outcomes, it is not possible to conclude that these markers of elevated exposure for this group confers any increased risk for cancer.

The issue of smokers in the cohorts and the inability to specifically identify individual smoking status is a limitation of the study. For firefighters, using a serum cotinine greater than $10 \mathrm{ng} / \mathrm{mL}$ to estimate smoker status, 87 of the 358 (24.3\%) firefighters with measured serum cotinine in the analysis groups could be described as smokers. In the asphalt paver cohort, five of the workers were nonsmokers, six smoked cigarettes, and one was a smoker who quit during the study. One of the nonsmokers chewed tobacco. This, taken within the context of the NIST smoker and non-smoker urinary PAH data, ensures that the data reported here can still be interpreted with relevance to the workplace exposure experience.

The WTC firefighter study had notable strengths and weaknesses. The main strength of the firefighter study is that it is a robust biomonitoring study reported on an occupational cohort during the initial weeks of exposure to a major fire, building collapse and urban disaster. Other key advantages of the study are the sheer number of compounds tested (110) and number of participant firefighters (318 exposed and 47 controls). The biomonitoring protocol to quantify chemicals in firefighter blood and urine was developed by the CDC's National Center for Environmental Health, Division of Laboratory Sciences. It should be noted that the reason special operations firefighters were not included in this study is because raw data was not available from this cohort.

In the asphalt paver exposure-reduction study, there were 480 asphalt paver urine samples which originated from only 12 workers. Since the urine samples were collected at different times of the day and after various methods of exposure mitigation, we used average urinary PAH concentrations in our analysis. However, since three of the four study weeks featured samples from varying methods of exposure protection (not typically used in current day-to-day practice), there is potential for the urine $\mathrm{PAH}$ results to be skewed to lower concentrations. The result is a potential underestimation of PAH levels in asphalt 
workers, working under nominal conditions.

Presumptive disability laws link a specific occupation with a disease or condition that has been shown to be a hazard associated with that occupation. By establishing an association, if an individual employed in the occupation covered by the presumption develops a disease or condition that is specified in the presumptive law, then that disease or condition is presumed to have come from that occupation. As such, the burden of proof shifts from the employee to the employer to establish that the condition was not in fact associated with the occupation but with an alternative cause.

Prior to 2002, firefighters were not automatically covered for medical expenses related to presumed occupationally induced cancer. Now $90 \%$ of firefighters in Canada and Australia have some coverage along with firefighters in 33 US states [27]. However, these policies stand in conflict with current epidemiological evidence that has failed to clearly indicate elevated cancer risks in this worker population. As well, there is a disparity between worker groups, where groups that may actually have higher exposures (such as asphalt pavers) receive no presumptive classification.

The biomarker data presented in this article suggest asphalt paver workers may be a target worker group for epidemiological investigation into the potential impact of PAH exposure on cancer outcomes due to their higher exposure. As well, industrial hygienists may be advised to seek better exposure mitigation procedures for asphalt paver workers as a precautionary measure to reduce exposure to PAHs, even though increased cancer risk from this exposure has not been established.

\section{Conclusion}

While firefighters did not demonstrate a substantial change in urinary PAH metabolite levels compared to control populations of smokers and non-smokers, asphalt pavers experienced concentrations that were in some cases increased by orders of magnitude compared to NIST controls. This may, in part, explain the failure of the epidemiological literature to demonstrate an increase in cancer risk for the firefighter population. Further research is recommended to evaluate potential health risks for asphalt pavers, due to their elevated exposure to PAHs.

\section{Acknowledgements}

Supported in Part by the National Institute of Occupational Safety and Health Sunshine Education Research Center.

\section{References}

[1] Baxter, C.S., Hoffman, J.D., Knipp, M.J., Reponen, T. and Haynes, E.N. (2014) Exposure of Firefighters to Particulates and Polycyclic Aromatic Hydrocarbons. Journal of Occupational and Environmental Hygiene, 11, D85-D91. https://doi.org/10.1080/15459624.2014.890286

[2] Mumtaz, M., Georgre, J., Charnley, G., LaVoie, E. and Wood, A. (1995) Toxicolog- 
ical Profile for Polycyclic Aromatic Hydrocarbons. ATSDR.

[3] Fent, K.W., et al. (2014) Systemic Exposure to PAHs and Benzene in Firefighters Suppressing Controlled Structure Fires. Annals of Occupational Hygiene, 58, 830845.

[4] World Health Organization (2010) Some Non-Heterocyclic Polycyclic Aromatic Hydrocarbons and Some Related Exposures. In: IARC Monographs on the Evaluation of Carcinogenic Risk to Humans, 92, 754-773.

[5] Hansen, E.S. (1990) A Cohort Study on the Mortality of Firefighters. British Journal of Industrial Medicine, 47, 805-809. https://doi.org/10.1080/15459624.2014.890286

[6] Baris, D., Garrity, T.J., et al. (2001) Cohort Mortality Study of Philadelphia Firefighters. American Journal of Industrial Medicine, 39, 463-476. https://doi.org/10.1002/ajim.1040

[7] Bates, M.N., Fawcett, J., et al. (2001) Is Testicular Cancer an Occupational Disease of Fire Fighters? American Journal of Industrial Medicine, 40, 263-270. https://doi.org/10.1002/ajim.1097

[8] Bates, M.N. (2007) Registry-Based Case-Control Study of Cancer in California Firefighters. American Journal of Industrial Medicine, 50, 339-344. https://doi.org/10.1002/ajim.20446

[9] Demers, P.A., Heyer, N.J. and Rosenstock, L. (1992) Mortality among Firefighters from Three Northwestern United States Cities. British Journal of Industrial Medicine, 49, 664-670. https://doi.org/10.1136/oem.49.9.664

[10] Demers, P.A., Checkoway, H., et al. (1994) Cancer Incidence among Firefighters in Seattle and Tacoma, Washington (United States). Cancer Causes \& Control, 5, 129 135. https://doi.org/10.1007/BF01830258

[11] Firth, H.M., Cooke, K.R. and Herbison, G.P. (1996) Male Cancer Incidence by Occupation: New Zealand, 1972-1984. International Journal of Epidemiology, 25, 14 21. https://doi.org/10.1093/ije/25.1.14

[12] Guidotti, T.L. (1993) Mortality of Urban Firefighters in Alberta, 1927-1987. American Journal of Industrial Medicine, 23, 921-940. https://doi.org/10.1002/ajim.4700230608

[13] Howe, G.R. and Burch, J.D. (1990) Fire Fighters and Risk of Cancer: An Assessment and Overview of the Epidemiologic Evidence. American Journal of Epidemiology, 132, 1039-1050. https://doi.org/10.1093/oxfordjournals.aje.a115745

[14] Kang, D., Davis, L.K., Hunt, P. and Kriebel, D. (2008) Cancer Incidence among Male Massachusetts Firefighters, 1987-2003. American Journal of Industrial Medicine, 51, 329-335. https://doi.org/10.1002/ajim.20549

[15] LeMasters, G.K., Genaidy, A.M., et al. (2006) Cancer Risk among Firefighters: A Review and Meta-analysis of 32 Studies. Journal of Occupational and Environmental Medicine, 48, 1189-1202. https://doi.org/10.1097/01.jom.0000246229.68697.90

[16] Ma, F., Fleming, L.E., et al. (2005) Mortality in Florida Professional Firefighters, 1972-1999. American Journal of Industrial Medicine, 47, 509-517. https://doi.org/10.1002/ajim.20160

[17] Ma, F., Fleming, L.E., et al. (2006) Cancer Incidence in Florida Professional Firefighters, 1981 to 1999. Journal of Occupational and Environmental Medicine, 48, 883-888.

[18] Toraason, M., Hayden, C., Marlow, D., Rinehart, R., Mathias, P., Werren, D., DeBord, G. and Reid, T.M. (2001) DNA Strand Breaks, Oxidative Damage, and 1-OH Pyrene in Roofers with Coal-Tar Pitch Dust and/or Asphalt Fume Exposure. International Archives of Occupational and Environmental Health, 74, 396-404. 
https://doi.org/10.1007/s004200100238

[19] Buratti, M., Campo, L., Fustinoni, S., Cirla, P.E., Martinotti, I., Cavallo, D. and Foa, V. (2007) Urinary Hydroxylated Metabolites of Polycyclic Aromatic Hydrocarbons as Biomarkers of Exposure in Asphalt Workers. Biomarkers, 12, 221-239. https://doi.org/10.1080/13547500601100110

[20] Sobus, J.R., McClean, M.D., Herrick, R.F., Waidyanatha, S., Oneymauwa, F., Kupper, L.L. and Rappaport, S.F. (2009) Investigation of PAH Biomarkers in the Urine of Workers Exposed to Hot Asphalt. Annals of Occupational Hygiene, 53, 551-560.

[21] Serdar, B., Lee, D. and Dou, Z. (2012) Biomarkers of Exposure to Polycyclic Aromatic Hydrocarbons (PAHs) and DNA Damage: A Cross-Sectional Pilot Study among Roofers in South Florida. BMJ Open, 2, e001318.

https://doi.org/10.1136/bmjopen-2012-001318

[22] Fustinoni, S., Campo, L., Cirla, P.E., Martinotti, I., Buratti, M., Longhi, O., Foà, V. and Bertazzi, P. (2010) Dermal Exposure to Polycyclic Aromatic Hydrocarbons in Asphalt Workers. Occupational and Environmental Medicine, 67, 456-463. https://doi.org/10.1136/oem.2009.050344

[23] McClean, M.D., Osborn, L.V., Snawder, J.E., Olsen, L.D., Kriech, A.J., Sjödin, A., Li, Z., Smith, J.P., Sammons, D.L., Herrick, R.F., Cavallari, J.M. (2012) Using Urinary Biomarkers of Polycyclic Aromatic Compound Exposure to Guide Exposure-Reduction Strategies among Asphalt Paving Workers. Annals of Occupational Hygiene, 56, 1013-1024.

[24] McClean, M.D., Rinehart, R.D., Sapkota, A., Cavallari, J.M. and Herrick, R.F. (2007) Dermal Exposure and Urinary 1-Hydroxypyrene among Asphalt Roofing Workers. Journal of Occupational and Environmental Hygiene, 4, 118-126. https://doi.org/10.1080/15459620701334756

[25] Rhomberg, L.R., Mayfield, D.B., Goodman, J.E., Butler, E.L., Nascarella, M.A. and Williams, D.R. (2015) Quantitative Cancer Risk Assessment for Occupational Exposures to Asphalt Fumes during Built-Up Roofing Asphalt (BURA) Operations. Critical Reviews in Toxicology, 45, 873-918. https://doi.org/10.3109/10408444.2015.1094450

[26] Edelman, P., Osterloh, J., Pirkle, J., Caudill, S.P., Grainger, J., Jones, R., Blount, B., Calafat, A., Turner, W., Feldman, D., Baron, S., Bernard, B., Lushniak, B.D., Kelly, K. and Prezant, D. (2003) Biomonitoring of Chemical Exposure among New York City Firefighters Responding to the World Trade Center Fire and Collapse. Environmental Health Perspectives, 111, 1906-1911.

[27] International Association of Fire Fighters (IAFF) (2016) Presumptive Law Coverage for Cancer. http://www.iaff.org/hs/phi/disease/cancer.asp 
Submit or recommend next manuscript to SCIRP and we will provide best service for you:

Accepting pre-submission inquiries through Email, Facebook, LinkedIn, Twitter, etc. A wide selection of journals (inclusive of 9 subjects, more than 200 journals)

Providing 24-hour high-quality service

User-friendly online submission system

Fair and swift peer-review system

Efficient typesetting and proofreading procedure

Display of the result of downloads and visits, as well as the number of cited articles Maximum dissemination of your research work

Submit your manuscript at: http://papersubmission.scirp.org/

Or contact odem@scirp.org 